\title{
Penyusunan Laporan Keuangan dan Perancangan Aplikasi Keuangan Untuk Usaha Kecil Menengah Studi Kasus pada D’Haus Cake
}

\author{
Fitra Oliyan ${ }^{1}$, Elfitri Santi ${ }^{2}$, dan Eka Rosalina ${ }^{3}$ \\ ${ }^{1}$ Jurusan Akuntansi, Politeknik Negeri Padang \\ Email:fitraoliyan@pnp.ac.id \\ 2 Jurusan Akuntansi, Politeknik Negeri Padang \\ Email: elfitrisanti@ymail.com \\ 3Jurusan Akuntansi, Politeknik Negeri Padang \\ Email: ekarosalinapnp@yahoo.com
}

\begin{abstract}
ABSTRAK
This study aims to design accounting applications for the preparation of financial statements at D'Haus Cake's business. The approach used in this research is a case study. The design process begins with studying the transactions and reports that D'Haus Cake's business needs in the form of purchase and sale transaction forms, and general journals. The required reports are in the form of all transaction journal records, ledgers, trial balances, profit and loss reports, and statements of financial position. After studying the system requirements, then proceed to the application development stage using Microsoft Access 2013 software. The next stage is to test the application to obtain adequate confidence in transaction processing by comparing the results of processing with manual calculations carried out. The implementation process is carried out by converting the initial data on the conversion date and making input transactions up to the company's operating date. After implementing and converting, the final stage is to carry out training for users and carry out a process of improvement and adjustment to the application based on the feedback received from users. The process of designing and implementing the application has been considered successful after the user states that the application has met all user needs and operates well.
\end{abstract}

Kata kunci: Design, Applications, Accounting, Report, Financial

\section{ABSTRAK}

Penelitian ini bertujuan untuk merancang aplikasi akuntansi untuk penyusunan laporan keuangan pada usaha D'Haus Cake. Pendekattan yang dilakukan pada penelitian ini adalah studi kasus. Proses perancangan dimulai dengan mempelajari transaksi dan laporan yang dibutuhkan usaha D'Haus Cake berupa formulir transaksi pembelian dan penjualan, dan jurnal umum. Laporan yang dibutuhkan berupa keseluruhan catatan jurnal transaksi, buku besar, neraca saldo, laba rugi, dan laporan posisi keuangan. Setelah mempelajari kebutuhan sistem tersebut kemudian dilanjutkan pada tahap pengembangan aplikasi menggunakan software Microsoft Access 2013. Tahap berikutnya adalah melakukan pengujian aplikasi untuk mendapatkan keyakinan yang memadai atas pemrosesan transaksi dengan membandingkan hasil pemrosesasn dengan perhitungan manual yang dilakukan. Proses implemenasi dilakukan dengan melakukan konversi data awal pada tanggal konversi dan melakukan input transaksi sampai pada tanggal operasi perusahaan. Setelah melakukan implementasi dan konversi, tahap akhir adalah melaksanakan pelatihan kepada pengguna dan melaksanakan proses perbaikan dan penyesuaian terhadap aplikasi berdasarkan umpan balik yang diterima dari pengguna. Proses perancangan dan implementasi aplikasi telah dianggap berhasil setelah pengguna meyatakan bahwa aplikasi telah memenuhi seluruh kebutuhan pengguna dan beroperasi dengan baik.

Kata kunci: Perancangan, Aplikasi, Akuntansi, Laporan, Keuangan 


\section{Pendahuluan}

Laporan keuangan adalah laporan yang menggambarkan kondisi keuangan perusahaan dalam suatu periode tertentu. Laporan keuangan memperlihatkan kinerja perusahaan, dan digunakan oleh pemilik atau pimpinan perusahaan dalam pengambilan keputusan apakah terus melanjutkan usaha atau tidak. Selain itu laporan keuangan juga dapat digunakan oleh pihak luar perusahaan seperti kreditur, investor dan pemerintah. D'Haus Cake merupakan perusahaan kecil menengah yang bergerak dibidang produksi kue, baik itu kue kering maupun kue basah, kue ulang tahun dan lain sebagainya. Awalnya produksi kue tersebut dilakukan berdasarkan pesanan, namun karena banyaknya permintaan dari pelanggan maka produksi kue dilakukan setiap hari dengan mempekerjakan karyawan sebanyak lima orang. Perusahaan juga telah menyewa satu unit toko untuk melayani kebutuhan pelanggan. Dalam menjalankan usahannya D'Haus Cake belum memiliki pencatatan pembukuan dengan baik dan benar, sehingga laba yang dimiliki tidak menggambarkan kondisi yang sebenarnya. Oleh karena itu perlu dibuatkan rancangan aplikasi keuangan untuk penyusunan laporan keuangan perusahaan yang sesuai dengan Standar Akuntansi Keuangan yang berlaku.

\section{Rumusan Masalah}

Berdasarkan observasi dan diskusi yang dilaksanakan dengan pemilik usaha D'Haus Cake dapat didefenisikan permasalahan yang dihadapi oleh pemilik yaitu belum memiliki pencatatan atau pembukuan yang sesuai dengan standar akuntasi keuangan, sehingga belum menggambarkan kondisi keuangan yang sebenarnya.

\section{Metode}

Metode yang digunakan untuk memberikan solusi atas rumusan permasalahan adalah Software Prototyping. Metode ini dipilih karena penulis sebagai pengembang aplikasi sudah memiliki informasi yang cukup jelas dan memadai terhadap kebutuhan pengguna, rancangan aplikasi yang akan dikembangkan dan waktu yang ditargetkan untuk menyelesaikan aplikasi juga cukup singkat. Menurut definisi dari Wikipedia, "Software prototyping is the activity of creating prototypes of software application, i.e,. incomplete versions of the software program being developed. It is an activity that can occur in software development and is comparable to prototypeing as known from other fileds, such as mechanical engineering or manufacturing". Metode ini menggunakan 4 langkah untuk mengembangkan sistem yaituL 1. Identifikasi kebutuhan dasar sistem, 2. Membangun prototype awal, 3. Review prototype dan 4 . Revisi dan penyempurnaan prototype menjadi software yang berfungsi sesuai dengan kebutuhan pengguna sistem.

\section{Identifikasi Kebutuhan Dasar Sistem}

Kebutuhan aplikasi yang akan dikembangkan untuk usaha D'Haus Cake dapat dirinci sebagai berikut: 1. Pengolahan transaksi pembelian, 2. Pengolahan transaksi penjualan, 3. Pengolahan transaksi jurnal umum, 4. Pengolahan catatan dan 5. Penyajian laporan keuangan dan pendukung. Seluruh pengolahan dan penyajian laporan dilaksanakan berbasis computer dengan dukungan DBMS. Aplikasi yang didisain harus mampu berjalan pada platform sistem operasi Microsoft Windows 10 
32/64 bit dan dapat dioperasikan secara multi user. Penomoran bukti transaksi dilakukan secara otomatis dengan memanfaatkan fasilitas autonumber.

\section{Pengembangan Prototype}

Prototipe aplikasi dikembangkan dengan Microsoft Access 2013. Tahap awal pengembangan dimulai dengan merancang tabel dan relationships antar tabel, kemudian dilanjutkan dengan disain forms dan query yang dibutuhkan untuk input data dan penyajian informasi. Pemrograman aplikasi sebagian besar dilakukan pada tahap pengembangan forms karena forms berkaitan dengan kegiatan input data dan pemrosesan data. Bahasa pemograman yang digunakan adalah Visual Basic for Application (VBA) yang merupakan bahasa pemograman yang sudah terpasang pada aplikasi Microsoft access 2013. Kode program ditulis untuk berbagai event yang terjadi pada objek forms seperti command button dan event current. Langkah terakhir adalah membuat berbagai laporan yang dibutuhkan dengan kebutuhan pengguna.

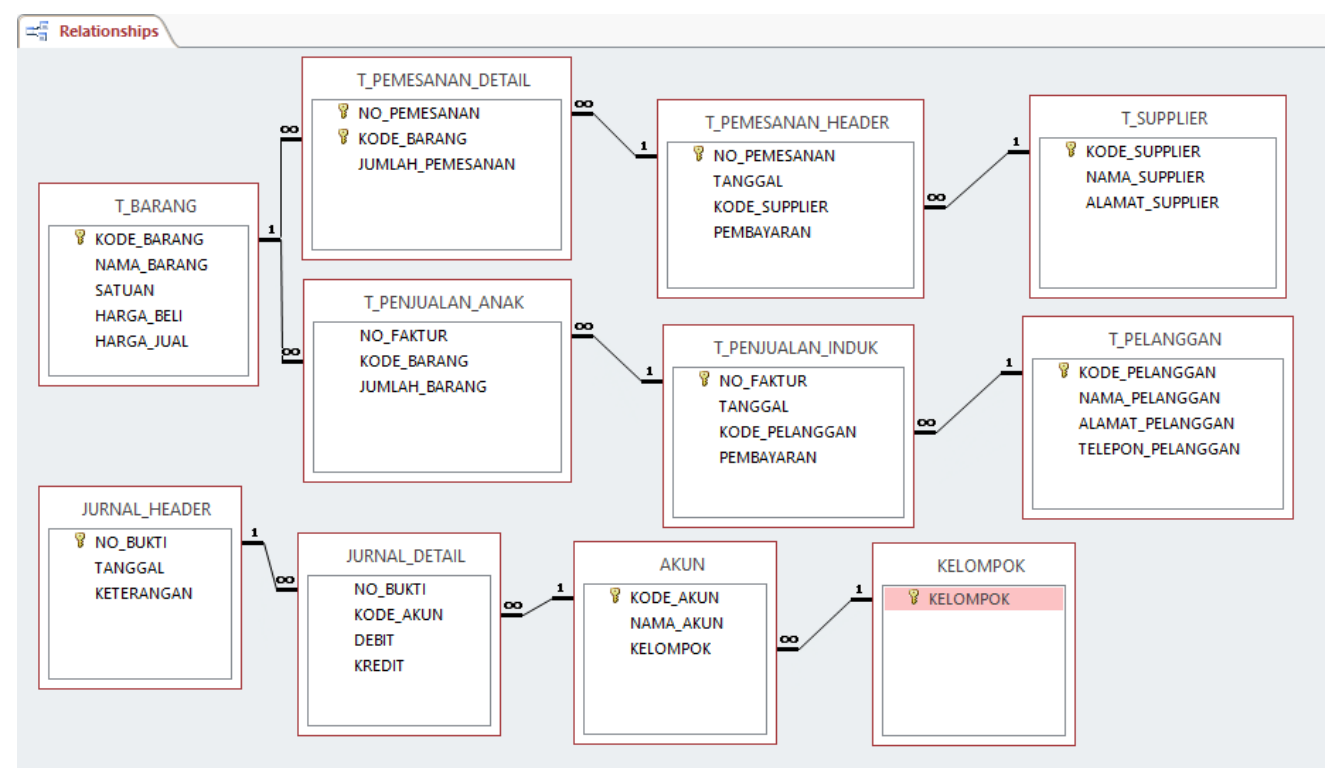

Gambar 1. Relationship antar tabel

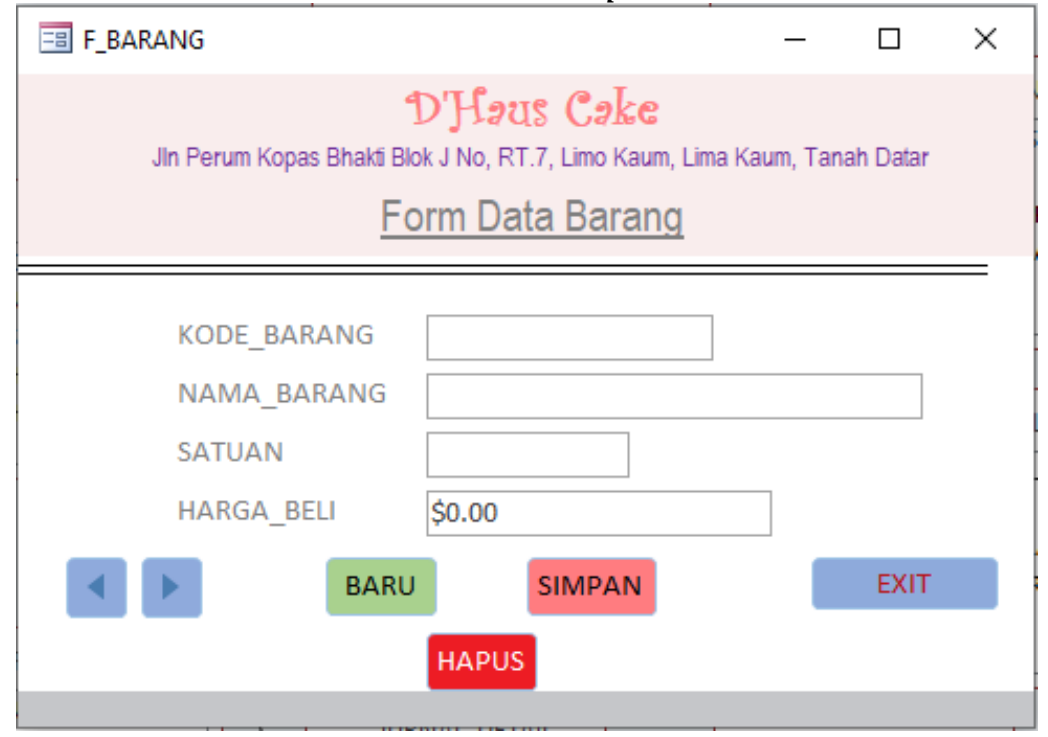

Gambar 2. Tampilan Form Data Barang 


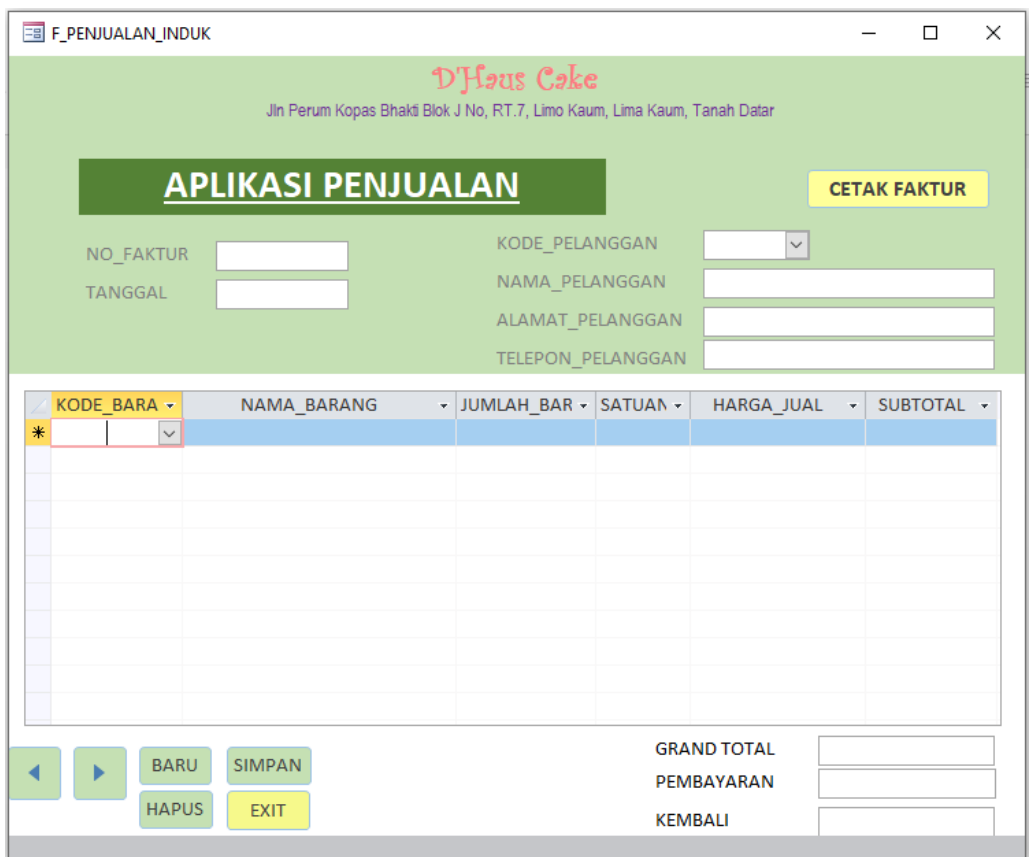

Gambar 3. Tampilan Aplikasi Penjualan

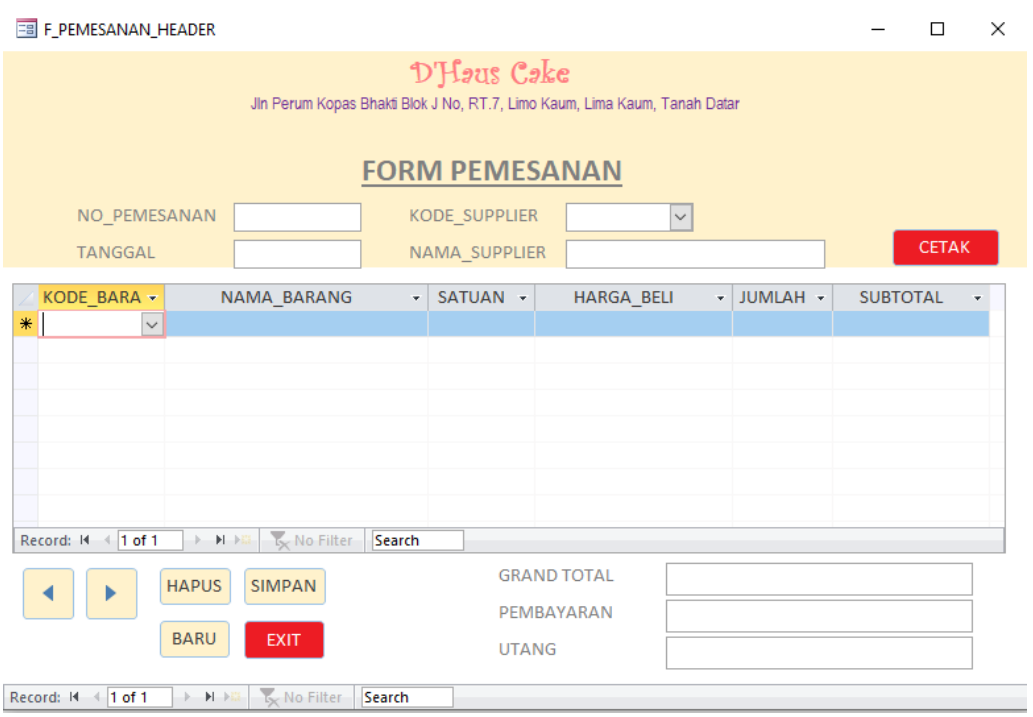

Gambar 4. Tampilan Form Pemesanan 


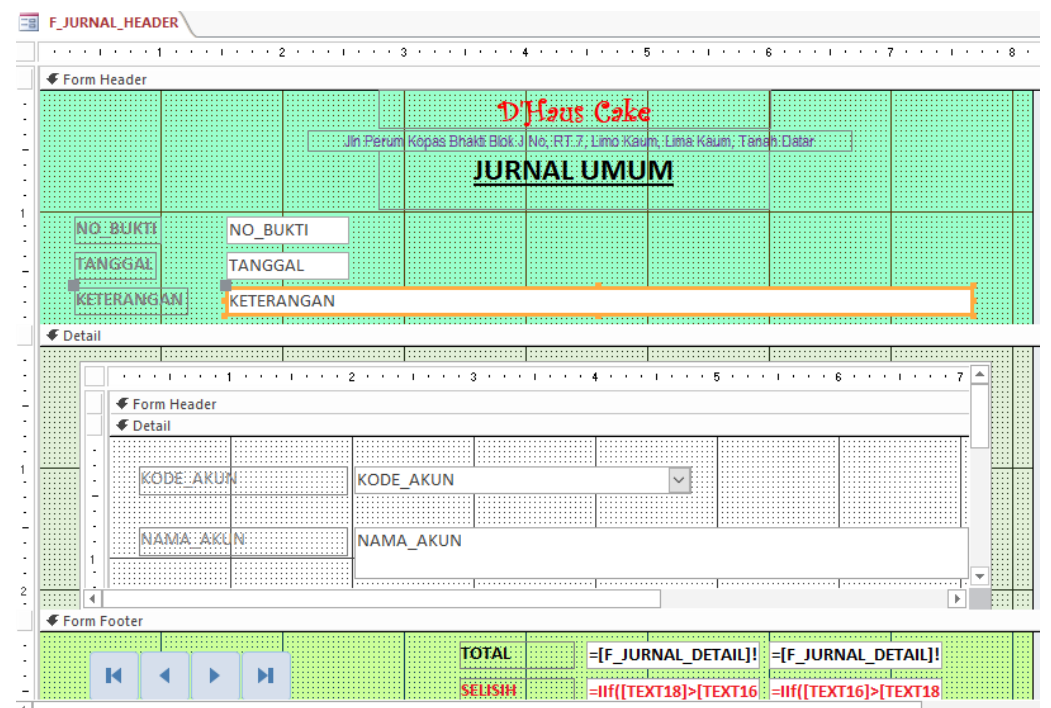

Gambar 5. Tampilan Disain Jurnal Umum

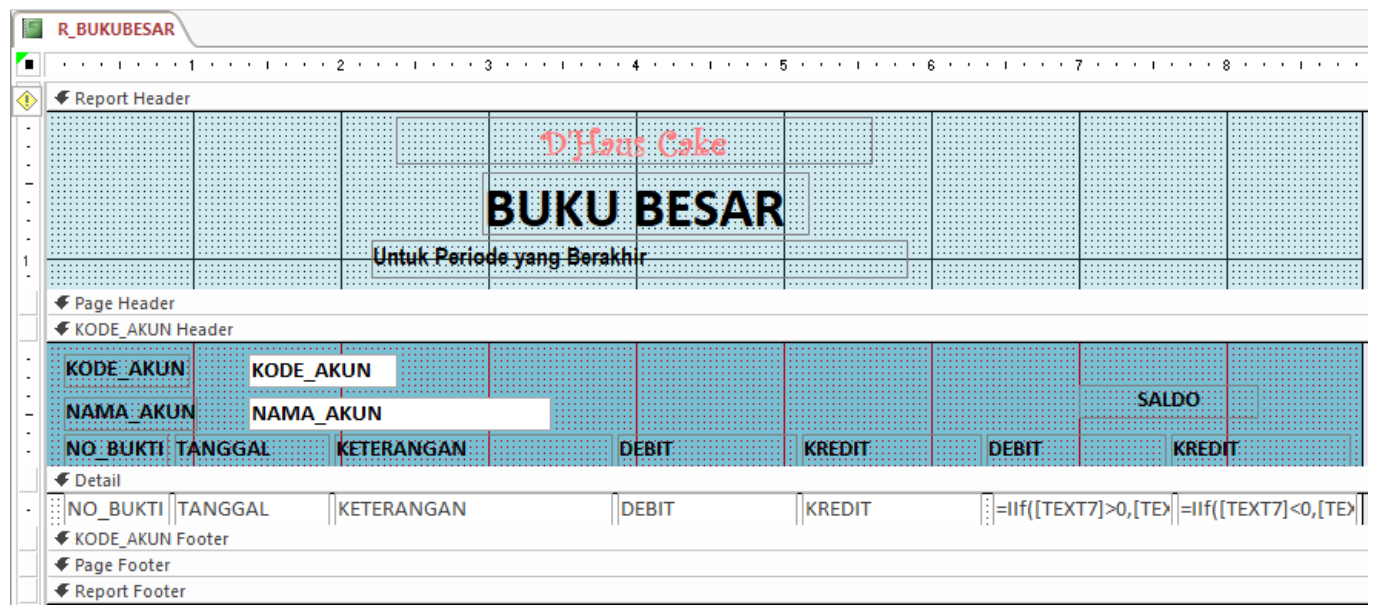

Gambar 6. Tampilan Disain Buku Besar

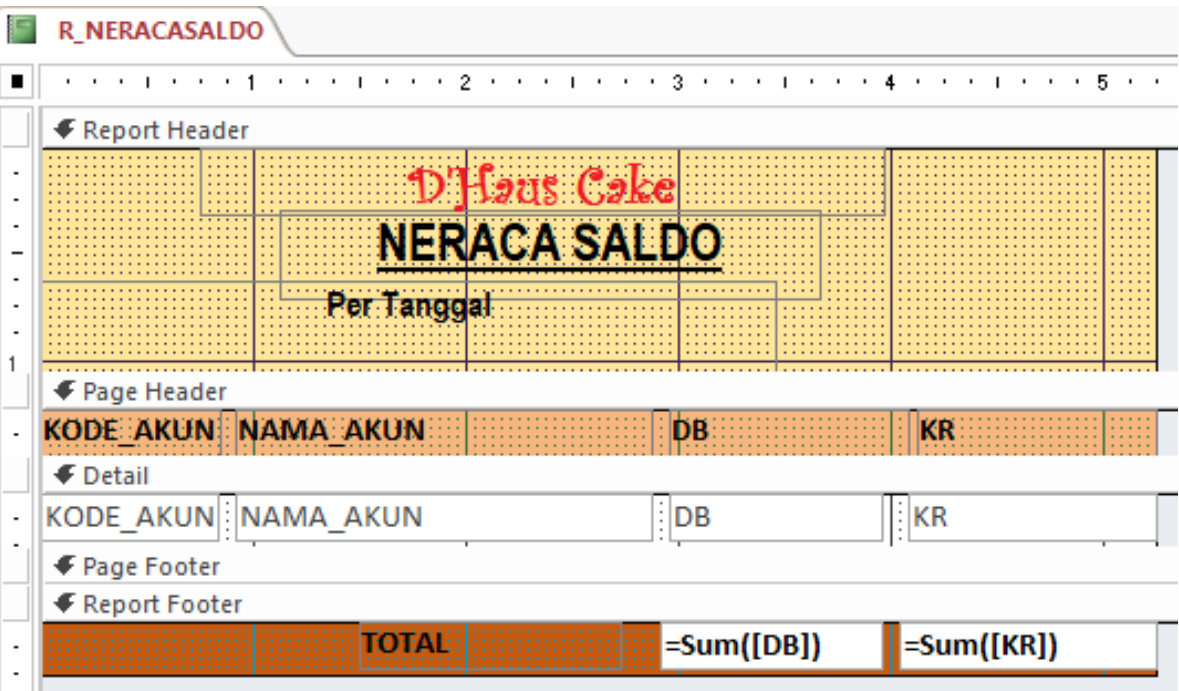

Gambar 7. Tampilan Disain Neraca Saldo 


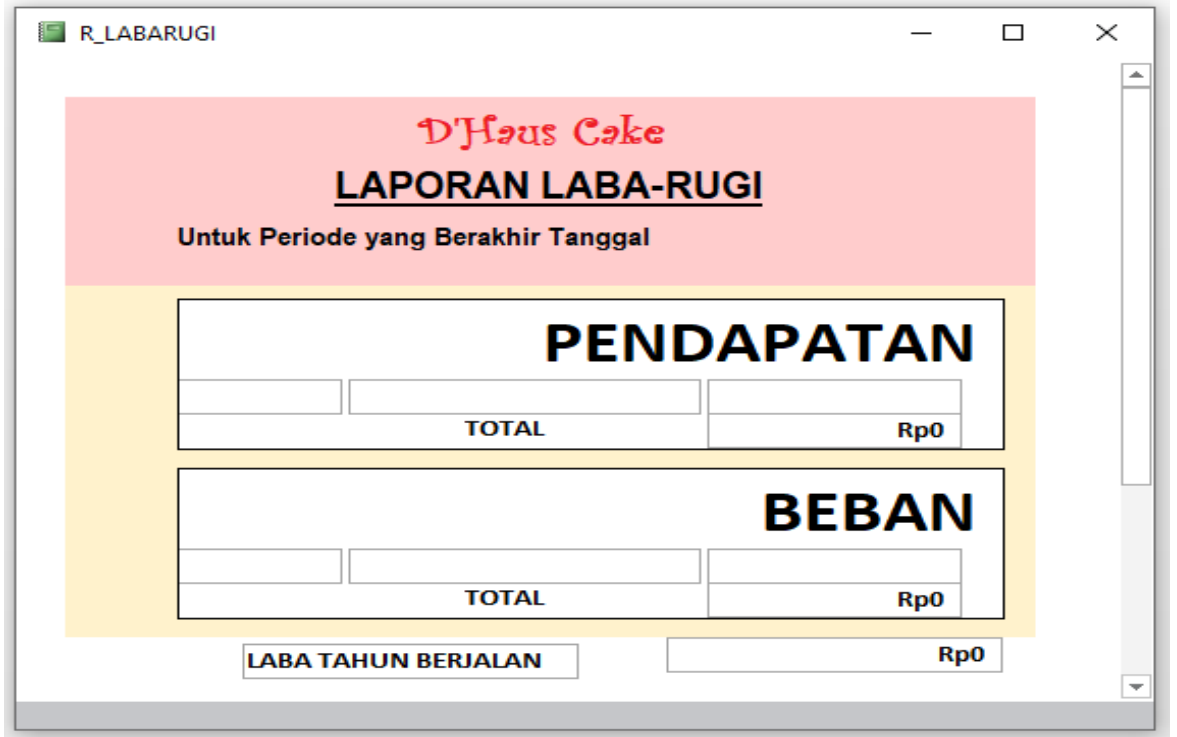

Gambar 8. Tampilan Disain Laporan Laba Rugi

D'Fe्यs Cake

LAPORAN POSISI KEUANGAN

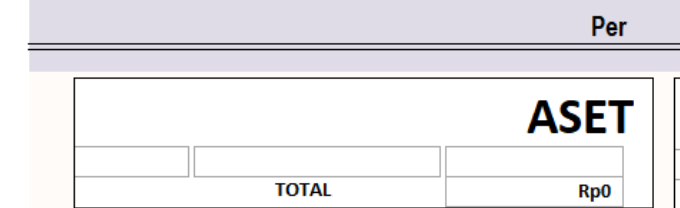

TOTAL ASET

LABA TAHUN BERJALAN

TOTAL KEWAIIBAN DAN EKUITAS

Rp0
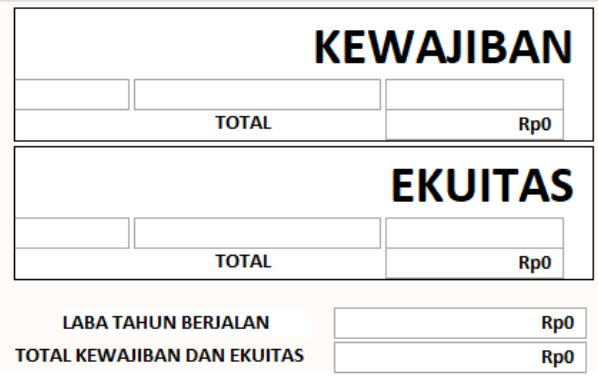

Gambar 9. Tampilan Disain Laporan Posisi Keuangan

\section{Reviu Prototipe}

Setelah prototype diselesaikan kemudian dilakukan reviu dan uji coba menggunakan data real. Langkah awal ini ditempuh agar proses migrasi dan konversi data dapat segera dilaksanakan dan mampu memberikan gambaran yang lebih nyata atas kemampuan aplikasi yang dikembangkan saat diberikan data transaksi. Hasil reviu yang dilaksanakan telah memberikan tingkat keyakinan yang memadai untuk menjalankan aplikasi pada basis pengolahan data yang sebenarnya.

\section{Revisi dan Penyempurnaan}

Berdasarkan hasil reviu yang telah dilaksanakan sebelumnya dan proses penggunaan aplikasi yang telah berjalan sekitar 1 bulan didapatkan keluhan dari pengguna untuk memberpaiki beberapa fungsi yang tidak berjalan sesuai dengan harapan, diantaranya kebutuhan pengguna agar data transaksi pada forms dapat ditampilkan secara urut sesuai dengan penomoran pada autonumber bukan sesuai dengan tampilan saat ini yang urut berdasarkan nomor bukti transaksi. Selain itu juga diatasi beberapa kendala teknis yang tidak terlalu signifikan. 


\section{Kesimpulan dan Saran}

Kebutuhan aplikasi pengolahan transaksi keuangan dan laporan keuangan telah berhasil dikembangkan pada Usaha Kecil Menengah yaitu D'Haus Cake dengan menggunakan Microsoft Access 2013 dengan metode prototyping dan berjalan dengan baik. Alasan pemilihan meotde ini karena kebutuhan dasar aplikasi sudah diidentifikasi dengan baik dan proses pengembangan aplikasi tersebut dapat dilaksanakan dalam waktu yang singkat. Sarannya adalah agar D'Haus Cake dapat secara konsisten dan berkelanjutan dapat menggunakan aplikasi ini agar laporan keuangan menggambarkan kondisi keuangan yang sebenarnya dan sesuai dengan Standar Akuntansi yang berlaku.

\section{Ucapan Terima Kasih}

Terimakasih penulis ucapkan kepada semua pihak yang telah membantu dan mendukung penelitian ini yaitu Politeknik Negeri Padang selaku institusi tempat penulis bekerja, P3M Politeknik Negeri Padang, dan tim pelaksana penilitian, sehingga penelitian ini dapat berjalan dengan baik dan memberikan hasil yang bermanfaat bagi pengguna aplikasi yaitu D’Haus Cake.

\section{Referensi}

wikipedia.org, Software Prototyping, diakses pada 2 November 2020, dari https://en.wikipedia.org/wiki/Software prototyping

Surya Firman, dkk (2017). Modul Praktikum Jobseheet Aplikasi Komputer. Jurusan Akuntansi Politeknik Negeri Padang, Padang.

Surya, Firman, dkk. (2020). Desain Aplikasi Sistem Informasi Akuntansi untuk Usaha Bengkel Studi Kasus pada AA Cempaka Auto Service. Jurnal Akuntansi dan Manajemen, Vol. 15, No. 1 